\title{
A rare balanced parental $t$ (21q; 21q) Robertsonian translocation that results in Down syndrome in all viable pregnancies
}

\author{
Seneesh Kumar Vikraman*, Vipin Chandra, Bijoy Balakrishanan, \\ Meenu Batra, Rekha Kuriakose, Gopinathan Kannoly
}

\begin{abstract}
Department of Feto-Maternal Medicine, Division of Obstetrics \& Gynaecology, CIMAR Edappal, Edappal Hospitals Pvt Ltd, Edappal, Malappuram-679576, Kerala, India
\end{abstract}

Received: 16 February 2015

Accepted: 01 March 2015

\section{*Correspondence:}

Dr. Seneesh Kumar Vikraman,

E-mail: drseneeshkv@gmail.com

Copyright: () the author(s), publisher and licensee Medip Academy. This is an open-access article distributed under the terms of the Creative Commons Attribution Non-Commercial License, which permits unrestricted non-commercial use, distribution, and reproduction in any medium, provided the original work is properly cited.

\begin{abstract}
We report a case of a rare balanced Robertsonian translocation, $\mathrm{t}$ (21q; 21q) in one of the parents that results in adverse pregnancy outcome in $100 \%$ of cases, either first trimester miscarriages or Down syndrome in all viable fetuses. The case highlights the role of optimum genetic evaluation of all cases of reproductive disorders as they can have profound effect over prognosis and further management.
\end{abstract}

Keywords: Robertsonian, Translocation, Karyotype, Down syndrome, Acrocentric

\section{INTRODUCTION}

Cytogenetics has made considerable progress ever since the correct set of chromosome number in human cells was identified as 46 in $1956 .{ }^{1}$ Chromosome abnormalities are now known to contribute significantly to the cytogenetic basis of reproductive loss, infertility, stillbirths, congenital anomalies, abnormal sexual development, intellectual disability and pathogenesis of malignancy. ${ }^{2,3}$

Chromosomal aberrations contributing towards human disease include numerical and structural abnormalities and to a lesser extent mosaicism and rarely chimerism. ${ }^{3,4}$ Numerical abnormalities include aneuploidies where the chromosome content of the cells is not an exact multiple of the monoploid set (23 for humans) e.g. 45, XO (Turner syndrome) and polyploidy where the chromosome content is $\geq 3$ times the monoploid set e.g. triploidy.

Structural abnormalities due to chromosomal breakage and rearrangement, may result in a balanced amount of genome (balanced) and includes inversions, translocations and insertions or unbalanced states include deletions, duplications, isochromosome, ring chromosome and dicentric chromosomes. ${ }^{3,5}$

Translocation is an exchange of genetic material between two different chromosomes, homologous or nonhomologous. Reciprocal translocations are usually an exchange of material between two nonhomologous chromosomes. Estimates of incidence range from about 1 in 500. Carriers of balanced reciprocal translocations have increased risks of creating gametes with unbalanced chromosome translocations, leading to miscarriages or cytogenetic/structural malformations.

Robertsonian translocation is caused by breaks at or near the centromeres of two acrocentric chromosomes (chromosomes with one arm much shorter than other namely group D - 13, 14, 15 and group $G-21,22$ ) with reciprocal exchange of parts gives rise to one large metacentric chromosome and one extremely small chromosome. $^{3}$ 
Down Syndrome (DS) is the single most common cytogenetic cause for intellectual disability. ${ }^{6}$ Approximately $95 \%$ of DS patients have trisomy 21 resulting from meiotic nondisjunction whereas $1 \%$ of DS is caused by mosaicism involving a mixture of normal diploid cells and trisomy 21 cells. $^{7}$

About $4 \%$ of DS patients have an unbalanced Robertsonian translocation involving chromosome $21 .^{8}$ Female carriers of balanced $14 / 21$ or $21 / 22$ Robertsonian translocations have a $10-15 \%$ risk for an unbalanced DS child. Male carriers have a risk of less than $5 \% .^{8}$

The rare parent who is a balanced $21 / 21$ isochromosome carrier which has an incidence of $0.019 \%{ }^{9}$ has a $100 \%$ risk for having a viable offspring with DS. We report one such case highlighting its cytogenetic aspects.

\section{CASE REPORT}

A 23 year old Indian woman presented in our clinic for pre conceptional counselling in view of a ten months old child with suspected DS along with her partner with whom she had a non-consanguineous marriage of two years. The couple did not have any difficulty in conceiving. She had a previous spontaneous miscarriage at six weeks. The present child was a born via caesarean section for fetal distress at 38 weeks. The past medical and surgical history of the couple was normal. Detailed family history was obtained and this too was negative.

Since the baby had phenotypic features of DS its karyotype was done. The result came as $46, \mathrm{XY},-21,+\mathrm{t}$ (21q; 21q) (Figure 1a). Since this was a rare karyotype finding, a repeat karyotype was done. The results were identical.

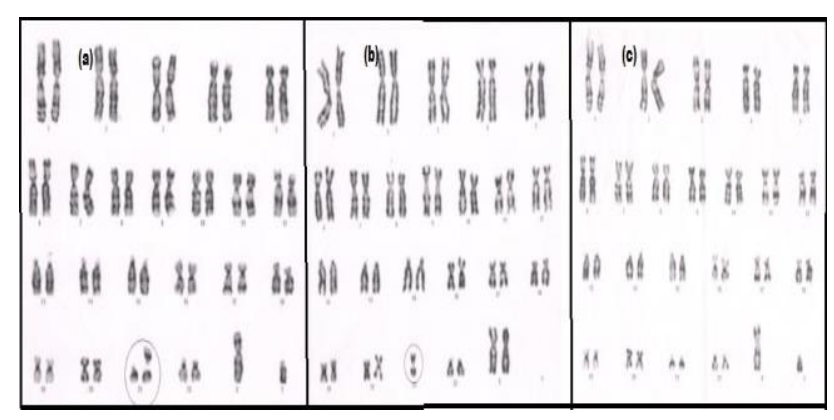

Figure 1: a) Karyotype of the child affected with translocation Down syndrome -46, XY, -21, +t (21q; 21q); b) Karyotype of mother, shows isochromosome 21 in circle; c) Father's karyotype, normal 46XY. All karyotypes were obtained by conventional Giemsa banding.

The couple were called for a genetic counselling session and the result was discussed. The need to do a karyotype of the couple was explained to determine the origin of the child's karyotype. After obtaining the consent from the couple, their karyotype was done. Mother's karyotype was found as 45, XX, -21, +21 der 21, t (21q; 21q) (Figure 1b). Father's karyotype was normal 46, XY (Figure 1c).

In the subsequent genetic counselling session the implication of the findings were discussed in detail. The need for donor oocyte/embryo In Vitro Fertilization (IVF) was emphasised as the only option for having a normal offspring.

\section{DISCUSSION}

Robertsonian translocation is named after William Rees Brebner Robertson who first proposed whole arm translocation in 1916 to correlate changes in chromosome morphology with certain taxonomic relations in insects. ${ }^{10}$ The reported frequency of Robertsonian translocation is $\sim 1$ in 1000 in the general population and thus in 500 couples. $^{11}$

Most commonly this occurs in non-homologous forms involving two different acrocentric chromosomes - either two different $\mathrm{D}$ group chromosomes (chromosomes 13, 14 and 15), two different $G$ group chromosomes (21 and 22 ), or a D group and a $G$ group chromosome. Approximately $60 \%$ of these translocations involve the long arm of chromosome 13, 14, or $15 .^{11}$ About half of these translocations are de novo and half are inherited from a balanced carrier parent (usually the mother). The most common translocation in humans involves chromosomes 13 and 14 and is seen in about $0.97 / 1000$ new-borns while the second most common is one between 14 and $21 .^{12}$

Nearly $40 \%$ of unbalanced Robertsonian translocations involve only chromosomes 21 and 22. Most of these (90\%) involve 21/21 long-arm fusions or isochromosomes. Only around 7\% of DS with t (21q; 21q) may have a carrier parent and mother usually is the carrier. ${ }^{13}$ Paternal transmission of $(21 \mathrm{q} ; 21 \mathrm{q})$ has also been reported. ${ }^{14}$

Mechanism of Robertsonian translocation is breakage of short arms of two homologous or non-homologous acrocentric chromosomes followed by centromeric fusion of the two long arms with suppression of one of the centromere. $^{15}$

Balanced Robertsonian translocation carriers have 45 chromosomes and are phenotypically normal, because the short arms mainly contain tandemly repeated satellite DNA sequences and the ribosomal RNA genes, which are present in all five pairs of acrocentric chromosomes. ${ }^{16}$ However there is a risk of unbalanced gametes that lead to miscarriages or abnormal offspring like reciprocal translocations. Carriers of Robertsonian translocations involving chromosome 21 have a particular higher chance of having a child with DS. The mother has a higher $(10 \%)$ risk of transmission than the father $(1 \%)$. Robertsonian translocations involving chromosome 14 
also carry a slight risk of uniparental disomy 14 due to trisomy rescue. ${ }^{3}$

Carriers of duplications of chromosome 21 cannot produce normal children because their gametes are either nullisomic or disomic; the risk of abortion or an infant with DS is $100 \% .^{17}$

At meiosis, these rearrangements form trivalents, segregation of which may result in gametes nullisomic or disomic for one of the chromosomes involved in the rearrangement and consequently to a zygote with trisomy or monosomy for one of the chromosomes involved (Figure 2). Zygotes with monosomy are not compatible with life and most translocation trisomy embryos are expected to result in first trimester loss or earlier; however, some survive beyond the second trimester and to term. ${ }^{11}$

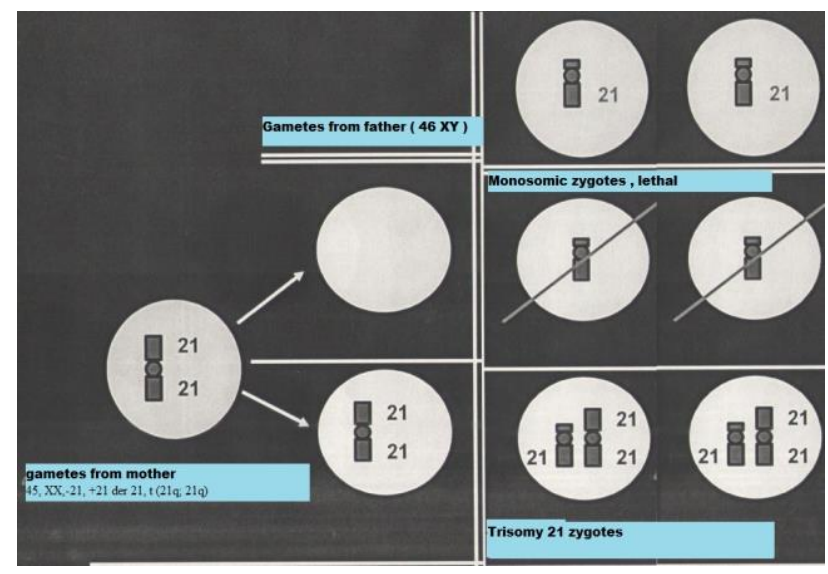

Figure 2: Gametes from mother are either Disomic for chromosome 21 or nullisomic. During fertilization, all the gametes will be either trisomy 21 or monosomic. The latter is lethal. Consequently all viable embryos will be trisomy 21 .

Abortions at an early gestational age have been attributed to monosomy and the fetuses are assumed to be nonviable. $^{18}$ The possible origin of $\mathrm{t}(21 \mathrm{q} ; 21 \mathrm{q})$ is de novo, germline mosaicism from one of the parents or from a carrier parent as in this case.

The only way to have a normal offspring for such a couple if the father carries such a structural rearrangement is artificial insemination and if the mother carries the rearrangement, ART with donor oocytes or donor embryos. Theoretically a carrier with a t (21q; 21q) can have normal offspring if his/her partner also carries the same translocation. ${ }^{19}$ The possibilities in this case are 21 tetrasomy, null chromosome 21 or like the parents a balanced $\mathrm{t}(21 \mathrm{q} ; 21 \mathrm{q})$. However this is practically difficult. Preimplantation genetic diagnosis which is otherwise a useful modality in couples with translocations does not have any role.

Cytogenetic assessment should be a part of evaluation of all couples presenting to the reproductive clinic. Once a cytogenetic abnormality is diagnosed, thorough genetic counselling should be offered by a team that is led by a geneticist. This enables the couple to make future reproductive decisions in ways best for them.

Funding: No funding sources

Conflict of interest: None declared

Ethical approval: Not required

\section{REFERENCES}

1. Barbara JT. Human cytogenetics: 46 chromosomes, 46 years and counting. Nature Rev Genet. 2002;3:769-78.

2. Kocarek E, Novatra D. Chromosome analysis in medicine. Cas Lek Cesk. 2002;141:12-5.

3. Gardner RJM, Sutherland GR. Down syndrome, other full aneuploidies, and polyploidy. In: Gardner RJM, Sutherland GR, eds. Chromosome Abnormalities and Genetic Counselling (Oxford Monograph on medical genetics). 3rd ed. New York : Oxford University Press; 2004.

4. Chen K, Chmait RH, Vanderbilt D, Wu S, Randolph L. Chimerism in monochorionic dizygotic twins: case study and review. Am J Med Genet Part A. 2013;161 A:1817-24.

5. NHGRI. Chromosome abnormalities, 2006. Available at: http://www.genome.gov/11508982. Accessed 28 January 2015.

6. Leonard H, Wen X. The epidemiology of mental retardation: challenges and opportunities in the new millennium. Ment Retard Dev Disabil Res Rev. 2002;8:117-34.

7. Freeman SB, Allen EG, Oxford-Wright CL, Tinker SW, Druschel C, Hobbs CA, et al. The national Down syndrome project: design and implementation 2007. Public Health Rep. 2007;122(1):62-72.

8. Boue A, Gallano P. A collaborative study of the segregation of inherited chromosome structural rearrangements in 1356 prenatal diagnoses. Prenat Diagn. 1984;4:45-67.

9. Chen CP, Chern SR, Tsai FJ, Wu PC, Chiang SS, Lee $\mathrm{CC}$, et al. Down syndrome due to unbalanced homologous acrocentric rearrangements and its recurrence in subsequent pregnancies: prenatal diagnosis by amniocentesis. Taiwan $\mathbf{J}$ Obstet Gynecol. 2009;48:403-7.

10. Daniel A, Lam-Po-Tang PR. Structure and inheritance of some heterozygous Robertsonian translocations in man. J Med Gen. 1976;13:381-8.

11. Keymolen K, Van Berkel K, Vorsselmans A, Staessen C, Liebaers I. Pregnancy outcome in carriers of Robertsonian translocations. Am J Med Genet A. 2011;155:2381.

12. Scriven PN, Flinter FA, Braude PR, Ogilbie CM. Robertsonian translocations - reproductive risks and indications for preimplantation genetic diagnosis. Hum Reprod. 2001;16(11):2267-73. 
13. Jayalakshamma, Margaret M, Amudha S, Tilak P, Devi R, Rajangam S. Cytogenetic analysis in Down syndrome. Int J Hum Genet. 2010;10(1-3):95-9.

14. Tolmie JL, MacFayden U. Clinical genetics of common autosomal trisomies. In: Tolmie JL, MacFayden U, eds. Principles and Practice of Medical Genetics. 5th ed. Philadelphia, USA: Churchill Livingstone-Elsevier; 2007: 1015-1026.

15. Han JY, Choo KHA, Shaffer LG. Molecular cytogenetic characterizations of 17 rob (13q14q) Robertsonian translocations by FISH - narrowing the region containing the breakpoints. Am J Hum Genet. 1994;55:960-7.

16. Emery AH, Mueller RF. Genetics and the physician. In: Emery AH, Mueller RF, eds. Elements of Medical Genetics. Student's Note. 8th ed. Edinburgh: Churchill Livingstone; 1992: 279-321.
17. Furbetta M, Falorni A, Antignani P, Cao A. Sibship. (21q 21q) translocation Down syndrome disorder with maternal transmission. J Med Genet. 1973;10:371-5.

18. Dallaire L, Fraser FC. Two unusual cases of familial mongolism. Can J Genet Cytol. 1964;6:540-7.

19. Ercis M, Balci S. Can a parent with balanced Robertsonian translocation t (21q; 21q) have a nonDown's offspring? Lancet. 1999;353(9154):751.

DOI: $10.5455 / 2320-1770.1 j r \operatorname{cog} 20150451$

Cite this article as: Vikraman SK, Chandra V, Balakrishanan B, Batra M, Kuriakose R, Kannoly G. A rare balanced parental t (21q; 21q) Robertsonian translocation that results in Down syndrome in all viable pregnancies. Int J Reprod Contracept Obstet Gynecol 2015;4:514-7. 